\title{
Drugstore chain operational efficiency evaluation based on DEA
}

\author{
JingYuan Han \\ College of Economics and Management \\ Hebei University of Science and Technology \\ Shijiazhuang050018,China \\ hanjingyuan163@163.com
}

\author{
GuoWei Yue \\ College of Economics and Management \\ Hebei University of Science and Technology \\ Shijiazhuang050018,China \\ 359603116@qq.com
}

\begin{abstract}
In this paper, the author studied the evaluation of drugstore chain store operational efficiency through practical research. This paper proposed DEA method to evaluate the pharmacy chain operational efficiency ---on the basis of established index system. According to DEA evaluation results, this paper concludes that there is a gap in the relative effectiveness of each pharmacy chain stores. And based on the technical efficiency of drugstore chain stores, this paper put them into three levels. And then, according to the corresponding pure technical efficiency and scale efficiency, analyze the elements of the input-output indicators of the stores. In the end, this paper suggests improvements to non-DEA efficient stores. This study shows that DEA model is effective to do evaluation of pharmacy chain stores operating efficiency, and hopes that the results of this study will provide a reference for the same industry.
\end{abstract}

Keywords- operational efficiency; chain pharmacies; DEA

\section{INTRODUCTION}

As China enters its twenty-first century, chain pharmacies, whether on the scale or quality have made rapid development, and the concentration of pharmacies also significantly enhances. However, some problems during the process of growth also attracted the attention. Chain pharmacy development is not only its scale; more important is its operational efficiency. And the stand or fall of operational efficiency directly affects the subsequent development of the enterprise, so the operating efficiency of chain pharmacies research is necessary.

Currently, in academia, the research about drugstore chain mainly refers to the study throughout the pharmacy industry. Operational efficiency research methods are mostly based on studies of other industries. It can be learned from other industries efficiency evaluation method, combined with the characteristics of chain pharmacies. Thus we can develop a complete set of operational efficiency evaluation system suitable for drugstore chain enterprises.

\section{LITERATURE REVIEW}

\section{A. Efficiency Evaluation Method}

Academic study of business efficiency began from Farrell's research in 1957, and he used the production function, cost function and profit function, that is, face frontier efficiency measurement and evaluation ${ }^{[1]}$.

Berger and Humphrey (1997) summarized five major efficiency evaluation methods, namely stochastic frontier method, the free distribution methods, thick frontier method of data envelopment analysis (DEA) and nonboundary method. Data envelopment analysis method and No boundary method both belong to non-parametric estimation method, in which no boundary analysis is a special case of data envelopment analysis. Berger and Humphrey considered that data envelopment analysis method has obvious advantages in terms of handling multiinput and multi-output ${ }^{[2]}$.

Chinese scholars do evaluation of the chain pharmacies from different angles, but main are pharmacy services, individual aspects of quality management processes, operational performance and GSP templates etc ${ }^{[3]}$. Such as Wang Shu-ling et al (2010) evaluated the performance condition of the pharmacy chain stores and initially established evaluation system ${ }^{[4]}$. Liu Zhong-yan (2013) use ultra-efficiency DEA to measure the operating efficiency of the hotel industry in 31 provinces during the period of 2006-2011.The results showed that the operating efficiency of the hotel industry had got an improvement in all provinces but the trend is not ideal in general, and proposed measures to improve the operating efficiency of the hotel industry from both macro and micro levels ${ }^{[5]}$.

To Summary the retail chains operating efficiency literature, in practical terms, the more similar the production process, inputs and outputs, the more convincing outcomes. And each pharmacy chain stores which this paper has studied complies the theoretical definition, so the author choose DEA method to do efficiency evaluation.

\section{B. DEA evaluation model}

Data envelopment analysis (DEA) is an important nonparametric method to evaluate productivity, made by Charnels, Cooper and Rhodes in 1978. Thomas (1998) ${ }^{[6]}$, Carlos Pentane, Carlos Alberto (2003) ${ }^{[7]}$, Chen Xin-hua (2006) ${ }^{[8]}$, respectively apply DEA method to evaluate the relative efficiency for retail food store operations, and the results indicated that data envelopment analysis is very effective to evaluate the retail chain stores catering. In addition, Ramakrishna (2009) used DEA and Malmquist Productivity Index to evaluate the operational efficiency for China's 61 retail enterprise and through Tobit regression analysis. The results showed that the characteristic of retail sales has played an important role in affecting the efficiency factor ${ }^{[9]}$. Li Xin-yun (2012) used DEA to evaluate the efficiency of science and technology 
investment in shandong industries. And the science and technology investment efficiency of industrial sector can be divided into DEA effective, weak DEA ineffective and seriously ineffective DEA three levels. And it is in line with the actual results ${ }^{[10]}$.

The object of this study is a set of homogeneous decision making units. And the principle is maintaining DMUs (Decision Making Units, DMU) input or output unchanged, with the help of mathematical programming methods to determine the relatively efficient production frontier. And then project each decision-making unit onto the surface of DEA production frontier, thus to evaluate the relative effectiveness between them by comparing the degree of deviation from the decision-making unit to the DEA frontier ${ }^{[1]}$.

\section{INDICATORS IDENTIFIED}

Academic research on the operational efficiency is less. And chain pharmacies belong to the retail pharmacy chain. So we can learn from academic research about other industries such as retailing and Chinese scholars' research on efficiency of business operations based on DEA. Now summarize the input-output indicators of academic scholars in Table 1.

TABLE I. THE SELECTION ABOUT INPUT-OUTPUT VARIABLES OF BUSINESS OPERATIONS EFFICIENCY

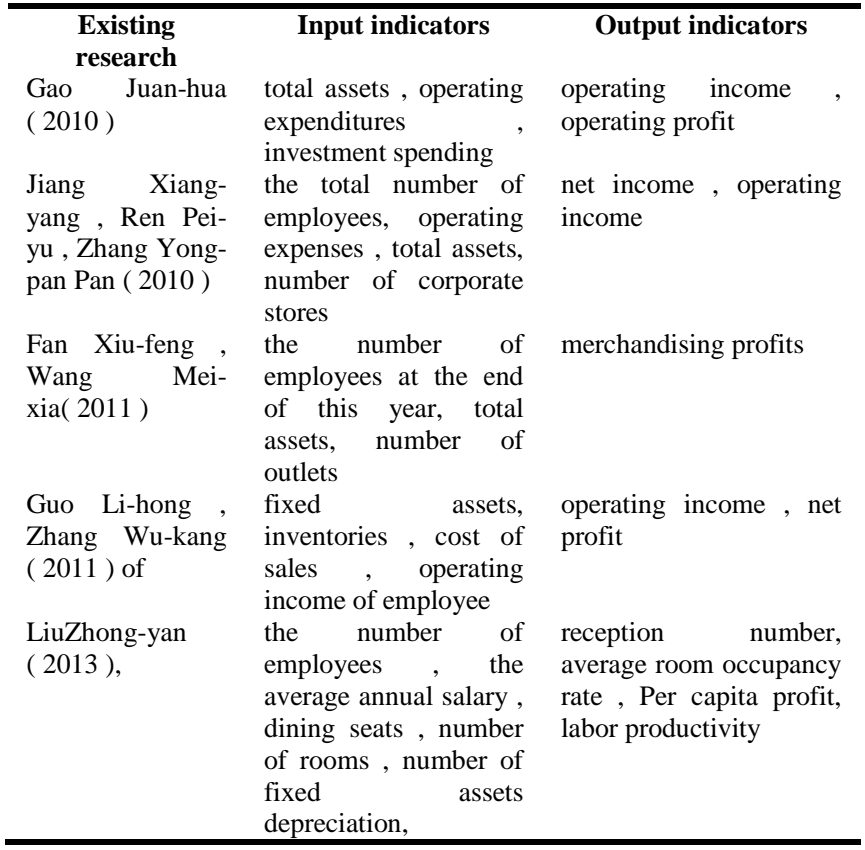

This paper summarizes the input and output indicators in Table 2.

TABLE II. INPUT-OUTPUT INDICATORS OF DRUGSTORE CHAIN OPERATIONAL EFFICIENCY

\begin{tabular}{ll}
\hline \multicolumn{1}{c}{ Input indicators } & \multicolumn{1}{c}{ Output indicators } \\
\hline Number of employees $\left({ }^{x_{1}}\right)$, the & Main business revenue $\left({ }^{y_{1}}\right)$, net \\
business area $\left({ }^{x_{2}}\right)$, inventories & profit $\left({ }^{y_{2}}\right)$ \\
$\left.x_{3}\right)$ & \\
\hline
\end{tabular}

\section{THE EMPIRICAL ANALYSIS OF DRUGSTORE CHAIN OPERATIONAL EFFICIENCY}

\section{A. Model Construction}

In this paper, all the stores of the chain pharmacy will be seen as decision-making units, denoted $A_{j}$.They contribute the input-output system with multiple inputs and outputs. Let $A=\left\{A_{j}, j=1,2, \cdots, n\right\}$ delegate unit set as $A, n$ is the number of chain stores.

Assume each decision unit has $m$ type of inputs and $S$ type of outputs, denoted as:

$$
\begin{aligned}
& x_{j}=\left(x_{1 j}, x_{2 j}, \cdots, x_{i j}, \cdots, x_{m j}\right)^{T}>0 \quad i=1,2, \cdots, m ; \quad j=1,2, \cdots, n \\
& y_{j}=\left(y_{1 j}, y_{2 j}, \cdots, y_{r j}, \cdots, y_{s j}\right)^{T}>0 \quad r=1,2, \cdots, s ; \quad j=1,2, \cdots, n
\end{aligned}
$$

Where, ${ }^{x_{i j}}$ represents the total amount of the $\mathrm{j}$ input of the $i$ decision making unit input indicators; ${ }^{y_{r j}}$ represents the total output of the $\mathrm{j}$ decision making unit of the $r$ decision making unit output indicators, and $x_{i j}>0, y_{r j}>0$.

Further set $v_{i}$ as a measure of input (right) of type i, $u_{r}$ as the $\mathrm{r}$ a measure of output (right) of type $\mathrm{r}$. The weight coefficient vector is:

$$
\begin{aligned}
& v_{i}=\left(v_{1}, v_{2}, \cdots, v_{m}\right)^{\mathrm{T}} \\
& u_{r}=\left(u_{1}, u_{2}, \cdots, u_{s}\right)^{\mathrm{T}}
\end{aligned}
$$

Definite the $\mathrm{j}$ decision making unit DMUj relative effectiveness index as:

$$
\begin{gathered}
h_{j}=\frac{u^{T} y_{j}}{v^{T} x_{j}}=\frac{\sum_{r=1}^{s} u_{r} y_{r j}}{\sum_{i=1}^{m} v_{i} x_{i j}} \\
j=1,2, \cdots, n
\end{gathered}
$$

Select the appropriate $\mathrm{u}$ and $\mathrm{v}$, and let $h_{j} \leq 1, j=1,2, \cdots, n$.

Evaluate decision-making unit of the $j$ ( $1 \leq j_{0} \leq n$ ), set $u$ and $v$ as the variables, the relative effectiveness of the index as the goal, all decisions relative effectiveness index unit as the bound, assuming constant returns to scale, and build CRS model. However, in many cases, this assumption can not be satisfied. To solve this problem, Banker, Charnes and Cooper proposed in 1984 the CRS model's improvement program that is VRS, also known as BCC model or C2GS2 model, which is divided into input and output types. Given the drugstore chain's own characteristics and its low-cost leadership strategy, this paper evaluates the pharmacy chain's stores relative effectiveness by DEA model based on inputs. 
Equation (2) is the VRS model based on inputs:

$$
\left(G^{1}\right)\left\{\begin{array}{c}
\min \theta=V_{G^{1}} \\
\text { s.t. } \sum_{j=1}^{n} \lambda_{j} x_{j}+s^{-}=x_{0} \\
\sum_{j=1}^{n} \lambda_{j} y_{j}-s^{+}=y_{0} \\
\sum_{j=1}^{n} \lambda_{j}=1 \\
\lambda_{j} \geq 0 \\
s^{+} \geq 0, s^{-} \geq 0
\end{array} \quad j=1,2, \cdots, n\right.
$$

\section{1)DEA effectiveness analysis}

DEA efficiency includes technology efficient and effective scale. The corresponding input $x$ is no longer reduced, under normal circumstances, when the output is ${ }^{y}$; this production process is called technology effectiveness. Sometimes when DMUs technology is effective, it does not mean that its DEA is effective .because there is a problem of returns to scale. Only when the Incremental investment ratio of inputs is equal to that of outputs, decision-making unit is in the best production scale. And this time we call its size is valid.

\section{2)Returns to scale analysis}

In equation (2), set the objective function $\min \theta=\theta^{*}$. When $\theta^{*}=1$, we call $D M U_{j 0}$ CRS model is effective, and

$$
\sum_{\text {If }}^{n} \lambda_{i}=1 \text {, then } D M U_{0} \text { is constant returns to scale; }
$$
scale;

$$
\sum_{\text {If }}^{n} \lambda_{i}<1 \text {, then } D M U_{0} \text { is increasing returns to }
$$

$\sum_{\text {If }}^{n} \lambda_{i}>1$, then $D M U_{0}$ is decreasing returns to scale.

In the model based on the inputs, processing slack variables with multi-stage is better than one-stage and twostage (two-stage). Therefore, this section uses a multi-stage (multi-stage) DEA model based on inputs (input oriented).

\section{B. Data Collection}

This paper focuses on a certain chain of pharmacies in 2012 to analyze the relative effectiveness of various stores. Data used is mainly from the financial data provided by the company and the author's firsthand by researching the enterprise.

\section{Data processing}

Since the input and output indicator-values have different dimensions and output indicators in the original data still exist negative, these data cannot be brought into the DEA model, So they need to be processed by dimensionless treatment. Then after treatment, the dates are within the range of 0.1 to 1 . Here are the specific methods to make raw data dimensionless:

- Set $\max z_{i j}=a_{j}{ }^{a_{j}}$ is the maximum value of the $j_{\text {indicator) }}$

$\min z_{i j}=b_{j} \quad\left(b_{j}\right.$ is the minimum of the $j_{\text {indicator })}$

- Then $z_{i j}^{\prime}=0.1+0.9 \times \frac{z_{i j}-b_{j}}{a_{j}-b_{j}}, z_{i j}^{\prime} \in[0.1,1]$

$z_{i j}^{\prime}$ is a value after a decision-making unit dimensionless process to the $j$ indicators in decision making unit $i$.

According to this method of dimensionless treatment for all index values, all the dimensionless values have been

\begin{tabular}{|c|c|c|c|c|c|c|}
\hline \multirow[b]{2}{*}{$\begin{array}{l}\text { The number } \\
\text { of Store }\end{array}$} & \multicolumn{3}{|c|}{ Output indicators } & \multicolumn{3}{|c|}{ Input indicators } \\
\hline & $\begin{array}{c}\text { Main } \\
\text { business } \\
\text { revenue ( } \\
\left.y_{1}\right)\end{array}$ & $\begin{array}{r}\text { Net } \\
\text { profit } \\
\left(y_{2}\right)\end{array}$ & & $\begin{array}{c}\text { Number of } \\
\text { employees }\left({ }^{x_{1}}\right)\end{array}$ & $\begin{array}{l}\text { Busine } \\
\text { ss } \\
\text { area } \\
\left(x_{2}\right)\end{array}$ & $\begin{array}{r}\text { Invent } \\
\text { ories }\left({ }^{x_{3}}\right) \\
\end{array}$ \\
\hline Shop 1 & 1.00 & 1.00 & & 1.00 & 0.18 & 1.00 \\
\hline Shop 2 & 0.70 & 0.75 & & 0.67 & 0.32 & 0.61 \\
\hline Shop 3 & 0.47 & 0.57 & & 0.42 & 0.12 & 0.21 \\
\hline Shop 4 & 0.27 & 0.37 & & 0.20 & 0.11 & 0.13 \\
\hline Shop 5 & 0.12 & 0.24 & & 0.10 & 0.10 & 0.11 \\
\hline Shop 6 & 0.16 & 0.17 & & 0.24 & 0.20 & 0.28 \\
\hline Shop 7 & 0.10 & 0.20 & & 0.13 & 0.11 & 0.10 \\
\hline Shop 8 & 0.14 & 0.23 & & 0.13 & 0.11 & 0.17 \\
\hline Shop 9 & 0.10 & 0.20 & & 0.10 & 0.13 & 0.11 \\
\hline Shop 10 & 0.14 & 0.10 & 602 & 0.38 & 1.00 & 0.81 \\
\hline
\end{tabular}
shown in table 3.

TABLE III. INPUT AND OUTPUT INDICATORS VALUES AFTER DIMENSIONLESS TREATMENT 


\section{ANALYSIS}

Bring the processed data into the DEA model and use the software DEAP2.1 to calculate. The results have been shown in Table 4

\section{A. overall analysis}

As we can see from table 4 that there are four stores that are relatively effective. And the remaining six are invalid. Overall, the average value of 10 stores technical efficiency is 0.802; pure technical efficiency is 0.875 ; scale efficiency is 0.918 . The results indicate that both pure technical efficiency and scale efficiency relate to the operational efficiency. From the point of scale revenue view, there are four stores keeping constant, one diminishing returns to scale, and the remaining five increasing returns to scale.

TABLE IV. THE DRUGSTORE CHAIN TECHNICAL EFFICIENCY, PURE TECHNICAL EFFICIENCY, SCALE EFFICIENCY AND RETURNS TO SCALE

\begin{tabular}{lllll}
\hline $\begin{array}{l}\text { Decision } \\
\text {-making } \\
\text { unit }\end{array}$ & $\begin{array}{l}\text { Technic } \\
\text { al } \\
\text { efficie } \\
\text { ncy }\end{array}$ & $\begin{array}{l}\text { Pure } \\
\text { techn } \\
\text { ical } \\
\text { effic } \\
\text { iency }\end{array}$ & $\begin{array}{l}\text { Scale } \\
\text { efficie } \\
\text { ncy }\end{array}$ & $\begin{array}{l}\text { Returns to } \\
\text { scale }\end{array}$ \\
\hline Shop 1 & 1.000 & 1.000 & 1.000 & Constant \\
Shop 2 & 0.812 & 1.000 & 0.812 & Decreasing \\
Shop 3 & 1.000 & 1.000 & 1.000 & Constant \\
Shop 4 & 1.000 & 1.000 & 1.000 & Constant \\
Shop 5 & 1.000 & 1.000 & 1.000 & Constant \\
Shop 6 & 0.494 & 0.528 & 0.936 & Ascending \\
Shop 7 & 0.771 & 1.000 & 0.771 & Ascending \\
Shop 8 & 0.841 & 0.919 & 0.915 & Ascending \\
Shop 9 & 0.833 & 1.000 & 0.833 & Ascending \\
Shop 10 & 0.273 & 0.298 & 0.915 & Ascending \\
average & 0.802 & 0.875 & 0.918 & \\
\hline
\end{tabular}

\section{B. Comparison of single-store}

\section{1)Technical Efficiency Analysis}

According to Table 4, the technical efficiency value of shop1, shop 3and shop 4 is 1.This indicated that these stores had being technical efficiency. They are not only technology effective, but also scale effective. Thus means that their operational efficiency is relatively well. The rest of the technical efficiency values of decision making units were less than 1, indicating that these stores are noneffective. According to their efficiency values, they have been arranged in descending order: Shop 8, Shop 9, shop 6 , shop 7, Shop 2, and shop 10. These non-DEA effective stores can be classified according to the degree of noneffectiveness:

The first level: the stores of relatively serious non-DEA effectiveness include: shop 6 and shop 10;

The second level: the stores of relatively moderate nonDEA effectiveness includes: Shop 7;

The third level: the stores of relatively non-DEA to a lesser extent include: Shop 2, shop 8 and shop 8.

As we can see from the DEA efficient stores, besides shop 5, the rest are medium-sized shop. And the relatively serious non-DEA stores are large-scale ones.
2)Pure technical efficiency and scale efficiency analysis

Stores usually have three sources of inefficiency: pure technical inefficiency, scale inefficiency, and both of them. This paper uses three sides to analyze the source of six stores'inefficiency in 2012.

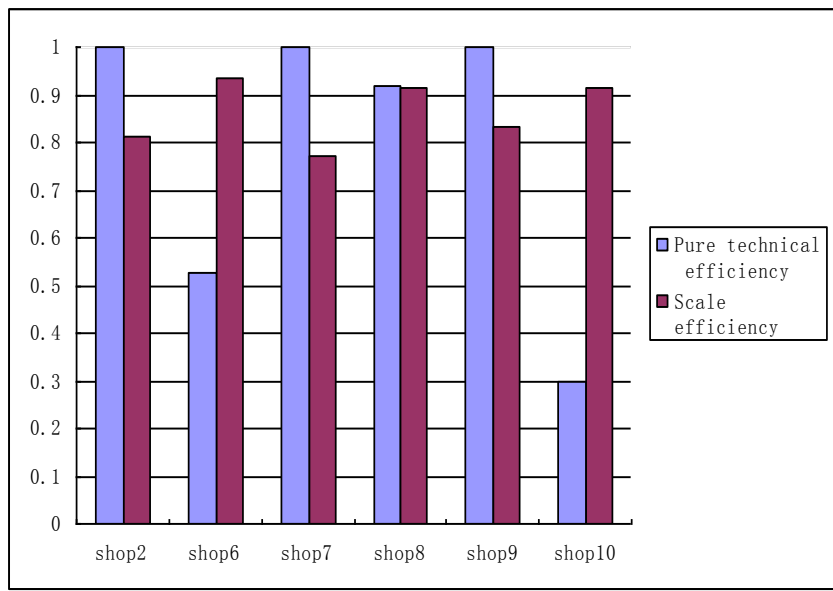

Figure 1. pure technical efficiency and scale efficiency of relatively ineffective stores of a certain chain drugstore in 2012

As we can see from Figure 1, the value of pure technical efficiency of Shop 2, Shop 7 and shop 9 were 1, which meat they were pure technology effective. It also describes that its technical capacity and operational capability of these three stores are adapted to meet its development needs. Technical inefficiency is usually due to the unreasonable scale of operation: too large or too small .And this eventually leads to the low efficiency of store operations; other values of three stores, whether it is pure technical efficiency or scale efficiency, they were less than 1. Technology efficiency depends both pure technical efficiency and scale efficiency, so in order to make the three stores achieve effective results, the drugstore should make efforts to improve the management level and large the scale of operations. The values of store 8 of pure technical efficiency and scale efficiency were more than 0.9 , indicating that its technical capabilities and the ability to scale and its operations were basically the same, but they needs to be improved. The value of scale efficiency of Shop 6 and 10 were more than 0.9 , but the pure technical efficiency were less than 0.6 , especially the value of shop 10 was less than0.3. So the priority is mainly to improve business capability, supplemented by improving its operational scale, thus to achieve technological efficiency improvement

\section{3) Analysis of returns to scale}

We can see from the non-technical efficiency source that the business efficiency of shop 2, shop7 and shop9 is caused mainly by scale inefficiency. Shop 2 was in the stage of decreasing returns to scale, indicating that its operational capacity could not meet its operating scale. In order to improve its efficiency, it needs to reduce the size. Shop 7 and 9 were both in the stage of incremental returns to scale, indicating that their operational capacity exceeds its scale of operations; it should expand the scale of operations. The remaining three stores were in the stage of increasing returns to scale, indicating their ability to operate beyond the current scale of operation. And it still has room for development. Therefore, diseconomies of 
scale are still one of the main factors affecting the operating efficiency of the pharmacy chain. In fact, a lot of companies in the expansion of the chain simply believe that there will be development, market, and Competitiveness as long as there is enterprises scale. And one-sided pursuit of expansion, sales volume increasing scale, while ignoring their own management and processing to enhance the level of relations with suppliers, will results to the rapid expansion of the scale but sharp decline of the efficiency.

\section{Improving non-DEA efficient unit}

In this paper, the author has obtained first-hand research data of the drugstore chain. The next will use DEAP2.1 software to do projection analysis to non-DEA decisions unit (Table 5 and Table 6), thus to improve them.

From the investment point of view, shop 6,8and10, have appeared redundant inventories, indicating that the two stores did not have full effect in the commodity management. Shop 6, 9 and 10 have appeared redundancy in the business area, indicating their ability to site selection, shop layout, design and other aspects need to be further improved. Shop 8 appeared redundant number of employees, reflecting the drugstore chain was still laborintensive enterprises, and information management was relatively backward.

TABLE V. TABLE 5 INPUT REDUNDANCY RATE CASE AND OUTPUT UNDEREMPLOYMENT RATE CASE

\begin{tabular}{|l|l|l|l|l|l|}
\hline \multirow{2}{*}{$\begin{array}{l}\text { Shop } \\
\text { number }\end{array}$} & \multicolumn{2}{|l|}{ firm } & \multicolumn{2}{|l|}{ firmut } & \multicolumn{2}{l|}{ output } \\
\cline { 2 - 6 } & $s_{1}^{-}$ & $s_{2}^{-}$ & $s_{3}^{-}$ & $s_{1}^{+}$ & $s_{2}^{+}$ \\
\hline Shop 1 & 0.000 & 0.000 & 0.000 & 0.000 & 0.000 \\
\hline Shop 2 & 0.000 & 0.000 & 0.000 & 0.000 & 0.000 \\
\hline Shop 3 & 0.000 & 0.000 & 0.000 & 0.000 & 0.000 \\
\hline Shop 4 & 0.000 & 0.000 & 0.000 & 0.000 & 0.000 \\
\hline Shop 5 & 0.000 & 0.000 & 0.000 & 0.000 & 0.000 \\
\hline Shop 6 & 0.000 & 0.003 & 0.032 & 0.000 & 0.105 \\
\hline Shop 7 & 0.000 & 0.000 & 0.000 & 0.000 & 0.000 \\
\hline Shop 8 & 0.001 & 0.000 & 0.041 & 0.000 & 0.029 \\
\hline Shop 9 & 0.000 & 0.030 & 0.000 & 0.020 & 0.040 \\
\hline Shop 10 & 0.000 & 0.197 & 0.129 & 0.000 & 0.157 \\
\hline average & 0.000 & 0.023 & 0.020 & 0.002 & 0.033 \\
\hline
\end{tabular}

From the output side, the output has appeared largely insufficient, mainly net profit. And the value of net profit of four stores, besides shop8, was larger than the average. This indicates that the drugstore chain's net profit have considerable room for improvement. Inadequate output of sales store has only one. And reducing staff in the existing investment and increasing inventory can increase sales. Net profit improvement is directly related to the gross margin and expenses. Shops should increase gross profit or decrease costs reasonably depending on the circumstances. Shop 2 had neither input redundancy nor output shortage, and this reflects that its management is better. But for its diminishing returns to scale, under the same circumstances, the output should be the same proportion to reduce the investment, in order to be effective.

\section{CONCLUSIONS}

Data envelopment analysis is an effective means for drugstore chain to do business efficiency of comparative analysis. This method can offer each DMU technical efficiency, pure technical efficiency and scale efficiency, and at the same time, offers pure shadow prices of inputs and outputs, etc..It can also give decision makers a means of system analysis and countermeasures. They can make plans in terms of efficiency evaluation and scale analysis.

Empirical analysis shows that the analytical results and the actual research are basically the same. And the degree of fit between the two lies depends on the level of input and output indicators selected. According to DEA analysis results we can find the existing problems of the corresponding input and output indicators elements. The results obtained through the analysis can be quantified by projection analysis to determine the values of investment elements needed to reduce and output elements need to be increased. And through the analysis of the state of its scale, this method can help companies to find the decisionmaking units of returns to scale of inefficient, and merge efficient stores and inefficient stores. Thus companies can achieve the purpose of having higher efficient stores, while avoiding the waste of resources and saving business costs.

The DEA method used and empirical analysis in this paper can be applied to evaluate the operational efficiency of the industry of drugstore chain and provide a reference for corporate decision-making and corporate institutions.

\section{REFERENCES}

[1] Farrell M J. The measurement of production efficiency [J]. Journal of Royal Statistical Society Series, 1957, 120(3): 253-290

[2] Berger A.N and D.B.Humphrey. Efficiency of frinancial international survey and directions for future reseach [J]. European Journal of Operational Research, 1997, (98): 175-212

[3] Lu shuang,Zhu Wen-tao.The progress of retail pharmacies evaluation system[J]. China Pharmacovigilance, 2010, 7 (9): 551553

[4] Wang Shu-ling, Sun Ya-nan, Analysis of the performance evaluation status of drugstore chain stores.China Pharmacist .2010,7 (8) :36-40

[5] Liu Zhong-yan. Measurement and evaluation of the operating efficiency of hotel industry based on the super-efficiency DEA model[J]. Hunan University of Science and Technology, 2013, 7

[6] Thoams, R. R., Barr, R. S., Cron, W.L.,et al. A process for evaluating retail store efficiency: a restricted DEA approach[J] International Journal of Research in Marketing, 1998(15): 487 503

[7] Barros C P, Alves C A. Hypermarket retail store efficiency in portugal [J]. International Journal of Retail \& Distribution Management, 2003, 31(11): 549-560

[8] Chen Xin-hui. DEA efficiency analysis of restaurant chain stores Performance[J]. Technology and Management, 2006 (6): 49-54

[9] Wan Tao-yu, Ramakrishnan Ramanathan.An assessment of operational efficiency of retail firms in China $[\mathrm{J}]$. Journal of Retailing and Consumer Services, 2009, 16 (2): 109-122

[10] Li Xin-yun. Efficiency evaluation of industry investment in science and technology based on DEA--Based on Shandong Province industrial sectors research. Industrial Technology \& Economy, 2012,4 